\begin{tabular}{|l|l|}
\hline Postprint Version & 1.0 \\
\hline Journal website & $\underline{\text { http://dx.doi.org/doi:10.1054/midw.1999.0195 }}$ \\
\hline Pubmed link & $\begin{array}{l}\text { http://www.ncbi.nlm.nih.gov/entrez/query.fcgi?.cmd=Retrieve\&db=pubmed\&dop } \\
\text { t=Abstract\&list_uids=11151556\&query_hl=18\&itool=pubmed_docsum }\end{array}$ \\
\hline DOI & 10.1054/midw.1999.0195
\end{tabular}

\title{
Variation in home-birth rates between midwifery practices in the Netherlands
}

\author{
THERESE A. WIEGERS ${ }^{1}$, JOUKE VAN DER ZEE ${ }^{2}$, JAN J.KERSSENS ${ }^{3}$ AND MARC J.N.C.KEIRSE ${ }^{4}$ \\ ${ }^{1} \mathrm{PhD}$, Research Fellow \\ ${ }^{2} \mathrm{PhD}$, Professor Maastricht University and Director NIVEL \\ ${ }^{3} \mathrm{PhD}$, Research Fellow, NIVEL (Netherlands Institute of Primary Health Care) POBox1568, 3500 BN \\ Utrecht, The Netherlands \\ ${ }^{4}$ MD,DPhil, FRACOG, FRCOG, Professor and Head of Department, Department of Obstetrics and \\ Gynaecology, The Flinders University of South Australia, Flinders Medical Centre, GPO Box 2100, \\ Adelaide, SA 5001, Australia
}

Objective: to examine the reasons for the variation in home-birth rates between midwifery practices.

Method: multi-level analysis of client and midwife associated, case-specific and structural factors in relation to 4420 planned and actual home or hospital births in 42 midwifery practices.

Findings: women's choice of birth location and the occurrence of complications that lead to referral to specialist care before or during labour, were found to be the main determinants of the home-birth rate. Yet, about $64 \%$ of the variation between midwifery practices is explained by midwife and practice characteristics. Higher home-birth rates were associated with a positive attitude to home-birth, a critical attitude to hospital birth for non-medical reasons, and good co-operation between midwifery practices and hospital obstetricians.

Conclusions: the proportions of planned hospital birth and of referral to specialist care are the most important predictors of the actual hospital-birth rate of women receiving midwifery care. Both can be influenced by the midwife through a positive attitude to home- birth, a critical approach to non-medical reasons for hospital birth, and good cooperation with specialist obstetricians. It is, therefore, important for midwives to be aware of the influence that their own attitudes may have on the choices their clients make about home or hospital birth.

\section{INTRODUCTION}

Obstetric care in the Netherlands is provided by primary caregivers: midwives or general practitioners (GPs), and by specialist obstetricians. Women with low-risk pregnancies receive antenatal care from midwives or, in some rural areas, from general practitioners. When they remain low risk throughout pregnancy they are free to decide for themselves where they want to give birth, at home or in hospital (short-stay), assisted by their own primary caregiver. Their midwife (or GP) will support them in their choice and attend the birth in the chosen place. Referral to specialist care will only happen in case of (threatening) complications.

In 1992 31.6\% of all births in the Netherlands took place at home, but there are considerable variations in home-birth rates between regions and between midwifery practices. For instance, the 
home-birth rate in Friesland, one of the northern provinces, was 41\%, while in Limburg, the most southern province, the home-birth rate was only $26 \%$ in 1992. At the level of regions these differences are related to population density and degree of urbanisation. In earlier research the degree of urbanisation was found to be an important factor in the variation in home- birth rates between regions (Hingstman \& Boon 1988). In urban areas the home-birth rate is lower than average: $21.3 \%$ in municipalities with 100000 or more inhabitants, rising to 39.5\% in municipalities with less than 5000 inhabitants (CBS 1995). In Sweden and Denmark a similar relationship was found during the shift from home to hospital birth earlier this century: in the more urbanised areas there was a high percentage of hospital births at an early point in time (Vallgårda 1996). Within these regions there is also variation in home-birth rates between midwifery practices. Indeed, even in geographically restricted areas there are large differences in home-birth rates between practices. This variation between practices is the subject of this study.

\section{Research question and hypotheses}

The central question in this analysis is: what determines the variation in home- and hospital- birth rates between midwifery practices? We expect the hospital-birth rate in each midwifery practice to be primarily determined by client characteristics, such as the number of clients who wish to give birth in hospital (the planned hospital-birth rate), or the number of clients who experience (threatening) complications that prompt referral to specialist care and thus to hospital birth. In comparison, the influence of the midwives themselves on the hospital-birth rate, through practice organisation, professional attitude, degree of co-operation with the nearest hospital and opinion on the appropriateness of home or hospital birth, may be only marginal. However, research on general practitioners has shown large inter-doctor-variations in referral rates to specialist care (Coulter et al. 1989, Newton et al. 1991). A similar inter-midwife- variation can be expected, not only in referral rates, but also in actual hospital- and home-birth rates in their practices.

When analysing differences in the actual hospital-birth rate between practices, known causes of variation in the planned hospital-birth rate must be taken into account. In 1991 the overall planned hospital-birth rate, as registered in the Dutch National Perinatal Database, was 42.4\% (SIG 1991). Factors that are known to influence the planned hospital-birth rate are:

- parity: nulliparous women plan a hospital birth more often than parous women; (in 1991 $47.8 \%$ of nulliparous and $37.1 \%$ of parous women planned a hospital birth (SIG 1991));

- age: younger women more often prefer a hospital birth (Kleiverda 1989, Kleiverda et al. 1990);

- obstetric history: women with a non-optimal obstetric history more often prefer a hospital birth (Wiegers et al. 1996);

- medical condition: women with minor physical complaints before or during pregnancy more often prefer a hospital birth than women with an optimal medical condition (Wiegers et al. 1996);

- degree of urbanisation: the hospital birth rate is higher in highly urbanised areas (Hingstman \& Boon 1988, CBS 1995);

- distance to the nearest hospital: the hospital birth rate is higher in practices closer to the hospital (Damstra-Wijmenga 1984).

When these known or expected influences are taken into account, the variation between practices in the planned hospital-birth rate may be explained by differences between midwives, for example their attitudes to home or hospital birth or their co-operation with the nearest hospital. To analyse these relationships four attitudinal variables have been introduced into the analysis: attitude to pregnancy and labour management, attitude to home-birth, attitude toward non-medical reasons for hospital birth, and attitude to consultation with obstetricians. We expect the home-birth rate to be higher (or the hospital-birth rate lower) in practices where midwives:

- have a more expectant (non-intervening) attitude to management of pregnancy and labour;

- have a more positive attitude to home-birth;

- are less inclined to recommend hospital birth for non-medical reasons;

- are more positive about their consultations with specialist obstetricians.

These expectations are partly based on findings from earlier studies. For example, a study on workload in midwifery practices found a correlation between midwives' attitudes to home- birth and 
non-medical reasons for hospital birth, and the actual home-birth rate (Jabaaij \& Meijer 1996). A study of co-operation between mid- wives and obstetricians, found a relation between the referral rates early and late in pregnancy, and the ensuing proportion of women giving birth in primary or secondary care (van der Lugt et al. 1991). We ourselves postulated that midwives with a more active attitude to management of pregnancy and labour would be more hospital- orientated than those with a more expectant attitude.

Because of referral to specialist care, before and during labour, of some of the women who had planned to give birth at home, in most practices the actual hospital-birth rate will exceed the planned hospital-birth rate. In analysing the actual hospital-birth rate, we therefore need to account for both the planned hospital- birth rate and the referral rate.

The factors associated with the variation in home-birth rates were summarily categorised as follows:

- women-associated factors (women's age, parity, preference for home or hospital birth);

- case-specific factors (obstetric history, referral to specialist care during pregnancy or labour);

- midwife associated factors (midwife's attitudes, working relationship with obstetricians);

- structural factors (degree of urbanisation, distance to the nearest hospital)

\section{METHODS}

\section{Participants}

The data used in this study are derived from a large project on midwifery care in one province of the Netherlands, Gelderland (Wiegers, 1997). For the analysis presented here, 73 midwives (of 99 independently practising midwives: response rate $74 \%$ ) in 42 practices participated, registering a total of 4420 births during six months in 1992. Each midwife completed a questionnaire about her background, practice organisation and professional attitudes. Attitudes were measured with lists of statements, for which they could indicate their degree of agreement. For instance, the attitude to pregnancy and labour management was measured with a list of actions or interventions a midwife might take to influence the pregnancy or labour process, such as prescribing a salt-restricted diet, sweeping of the membranes to stimulate contractions, performing episiotomy, or administering medication in the third stage of labour. Midwives were asked to indicate whether they performed these interventions (very) often, sometimes, or (almost) never. Based on these answers the midwives were attributed an active, intermediate or expectant attitude to pregnancy and labour management.

The attitude of midwives to home-birth was measured with a list of seven items - the home/ the hospital is: midwife-friendly, client-friendly, child-friendly, efficient, appropriate, hygienic, and safe when complications occur. Answers were given on a five-point scale, ranging from 'very much' to 'not at all'. Midwives' attitudes about advising their clients to choose hospital birth for non-medical reasons were measured with a eight-item list: no running water close to the bedroom, being nulliparous, language barrier, house too crowded, lack of self confidence, living in a fourth floor apartment without elevator, the woman is very anxious about the delivery, and no maternity care assistant avail- able. Again answers were given on a five-point scale, ranging from 'never' to `always'.

Assessment of consultations with obstetricians was measured with four items: the atmosphere during consultations is agreeable, the consultations are instructive, the atmosphere during consultations is constructive, and the obstetricians are paternalistic, with answers ranging from 'very much so' to `not at all'.

Client data were collected from birth registration forms, that are routinely used by midwives. The majority of the 4420 births (65\%) were planned home-births, but only $49 \%$ actually occurred at home, so the actual hospital-birth rate was $51 \%$. As expected, the variation was large. The lines in Figure 1 show that in three practices the actual hospital-birth rate was less than $20 \%$, while also in three practices the actual hospital-birth rate was higher than $80 \%$. The planned hospital-birth rate with an average of $35 \%$, varied similarly, with the lowest at $6 \%$ and the highest at $83 \%$.

\section{[ FIGURE 1 ]}

In the 42 practices in the study the referral rates during pregnancy varied from 0 to $44 \%$ (mean 13\%) and the referral rates during labour from 4 to $36 \%$ (mean 20\%). 


\section{Operationalisations}

The dependent variables are the planned hospital-birth rate and the actual hospital-birth rate. These variables are derived from the birth registration forms. Independent variables are client's characteristics, case-specific data, mid- wife/practice characteristics and structural factors (see Tables 1 and 2).

\section{[ TABLES 1-2 ]}

\section{Client's characteristics}

Age and parity were derived from the birth registration forms. For age two dummy variables were constructed: $<25$ years and $>31$ years, with the middle group as reference category. In the analysis of the actual hospital-birth rate, the planned place of birth was also regarded as an independent variable.

\section{Case-specific data}

Medical condition and obstetric history were also derived from the birth registration forms, but transformed to dichotomous variables with value $0=$ optimal and $1=$ non-optimal (the term 'optimal' is used to indicate the absence of problems in medical and obstetric history that might influence the pregnancy outcome) and referral status, using dummy variables for referral during pregnancy and referral during labour with reference category 'no referral'.

\section{Midwife/practice characteristics}

Number of midwives per practice, attitude to pregnancy and labour management (three-point scale, eight items, Cronbach $\alpha=0.62$ ), attitude to home-birth (five-point scale, seven items with Cronbach $\alpha=0.79$ ), opinion on non-medical reasons for preferring hospital birth (five-point scale, eight items, Cronbach $\alpha=0.71$ ) and assessment of the consultations with obstetrician (three-point scale, four items, Cronbach $\alpha=0.81$ ). These variables were measured at the level of the individual midwives and aggregated to the practice level, that is in practices with two or more midwives their answers were combined to one practice-answer.

\section{Structural factors}

For the degree of urbanisation two dummy variables were constructed, one for small towns and one for larger cities with rural areas as reference category. Distance to the nearest hospital was measured in minutes (by car).

\section{Statistical analysis}

The case-specific and client associated factors were collected per individual woman, while the structural and midwife-associated factors were collected at midwife/practice level. The data set, therefore, is structured as a hierarchy, containing data at two different levels, the practice level, with 42 cases, and the client level, with 4420 cases; with the client data nested within the practice data because each client is registered in only one practice. While it is possible to aggregate or combine the individual client data to the practice level, valuable information, namely the variation within each practice, would be lost by doing so. On the other hand, attributing practice characteristics to the individual level carries a risk of overestimating practice characteristics, because they would be included 4420 times instead of 42 times. In both cases we will not be able to distinguish between variations caused by different practice populations, that is by individual differences among clients, or variations caused by different practice characteristics (differences between midwives or groups of midwives). However, advanced software has become available to deal with this problem: multilevel statistical models (Woodhouse et al. 1995; Rice \& Leyland 1996). In these models, the effects of individual characteristics and group characteristics are estimated simultaneously, together with their interactions, which make it possible to partition the variation in the response of interest into that attributable to individual factors and that attributable to higher level factors (Rice \& Leyland 1996).

Since both dependent variables are binary, planned hospital birth or not and actual hospital birth or not, two series of logistic multilevel analyses were performed. Firstly, to explain the different rates of planned hospital birth between different practices, we started with a simple model (model A in Table 3) to establish the base-line chance of planning a hospital birth. In this simple model no explaining variables are included, so it reflects the raw data we have already presented: a large variation in 
planned hospital-birth rates between practices of $68 \%$ (bottom line in the Table 3). Subsequently, the different variables were introduced; first the client characteristics and the case-specific variables, then the structural factors and finally the midwife/practice characteristics (model B through model D in Table 3), leading to four different models with an increasing number of explanatory variables. The same procedure was then applied to explain the different rates of actual hospital births (models A through E in Table 4).

\section{[ TABLE 3-4 ]}

Our hypothesis was that midwifery practices differed in home/hospital-birth rates only be- cause of case-specific variables or client characteristics. If this hypothesis is correct, the variation we find between the practices should decrease when including client characteristics and case-specific variables in the model but remain at the same level when structural factors and midwife/practice characteristics are added. Therefore, in the Findings section, emphasis is on the coefficient which indicates the variation between practices.

\section{FINDINGS}

Before discussing the findings of the multi-level analyses, the data concerning the midwifery practices are presented to draw a picture of the average midwifery practice, the midwives' attitudes to management of pregnancy and labour, home or hospital birth, consultation with obstetricians and advising their clients to choose a hospital birth.

\section{Midwife/practice characteristics}

The 73 midwives, 71 women and two men, were self-employed in 42 midwifery practices: 21 solo practices, 15 shared practices and six group practices with three or four midwives. The average age of the midwives was 39 years in 1991, with $25 \%$ being 30 years or younger and $10 \%$ older than 52 years. The average practice had between 150 and 200 births a year; only three practices had less than 100 births a year and eight practices had more than 250 births a year. The nearest hospital was, on average, 9 kilometres away or a 12 minutes' drive by car, with a maximum of 25 kilometres or a 24 minutes' drive. Only two practices exceeded a distance of 20 kilometre (20 minutes) to a hospital.

The attitude of the midwives to pregnancy and labour management was classified as 'active' (23.2\%), 'intermediate' (46.4\%), and 'expectant' (30.4\%). All practising midwives had regular consultations with several obstetricians, six on average, but the frequency of these consultations varied from once a year to twice a week, with an average of once every two weeks. The overall assessment of these consultations was 'positive' in 33.9\% of practices, 'negative' in 30.5\%, and 'intermediate' in $35.6 \%$.

The attitude of midwives to home-birth was, on average, very positive. The combined score for attitude toward home-birth ranged from 1 (very positive) to 3 (intermediate), with a mean of 1.77 (s.d.=0.45). Midwives reported that they very seldom advised their clients to choose hospital birth for non-medical reasons. The combined score for advising hospital birth for non-medical reasons ranged from 1 (never) to 3.75 (frequently) with a mean of 1.97 (s.d. $=0.61$ ).

\section{Variation between practices}

The variation in planned and actual hospital- birth rate in the midwifery practices, as shown in Figure 1, was analysed by means of multilevel analysis, using a logistic regression model, with two levels: the pregnant women at level 1 and the midwifery practices at level 2. A logistic model is used, because probabilities are analysed. A probability can only have a value between 0 and 1 . A logistic transformation is needed to prevent those probabilities achieved being impossible values (less than 0 or more than 1). This means that the model estimates in the analyses are log odds and the between practice variance is given on a logit scale.

First the variation in planned hospital-birth rate was analysed, as shown in Table 3. The first model (A) in this analysis does not include explanatory variables. The variation among practices in planned hospital birth rate is 0.68 . Including client characteristics and case-specific factors (model B) does not change the variation among practices, although all variables, except the dummy for age $>31$, are statistically significant. This means that, although these variables are important determinants of the planned place of birth, they did not differ between practices. In other words, the proportions of 
younger women, nulliparae, women with a non-optimal obstetric or medical history were approximately equally spread across all practices. Consequently, these variables cannot ex- plain the variation between practices.

The variation between practices decreases from 0.68 to 0.58 (in model C) when structural factors are added to the model. This indicates that the distance to the hospital was a significant factor in explaining the differences between practices, with practices where the distance to the hospital was larger, the hospital-birth rate was lower. When the midwife/practice variables are included (model D) the variation between practices decreases further to 0.27 , with the attitude of midwives to home-birth and to non- medical reasons for hospital birth as significant determinants. This indicates that both a less positive attitude to home-birth and a more positive attitude to recommend hospital birth are related to higher hospital-birth rates. When analysed for nulliparous and parous women separately the same relationships were found, except that obstetric history was not applicable for nulliparous women and medical condition was found to be of significance for parous women only. The variation in model $\mathrm{D}$ is $39.7 \%$ of that in model B (0.27/0.68), so $39.7 \%$ of the initial variation is still unexplained, but $60.3 \%$ of the variance is explained by the structural and midwife variables. The differences between models A through D are statistically significant according to the likelihood statistics.

In the second analysis the actual hospital-birth rate is the dependent variable. Again, the first model is without explanatory variables and shows a variation between practices of 0.56 . The second model shows the variation in the hospital-birth rate between practices, controlled for variations in the planned hospital birth and referral rates before and during labour. This increases the variation in actual hospital-birth rate among practices from 0.56 to 0.87 . So, the variation across practices increases after the introduction of some of the case-specific variables. This can be explained by the fact that there are differences between practices in the number of women referred to specialist care just before or during labour, as well as in the number of women who planned to give birth in hospital. As noted before, these two factors are related: the referral rate was higher in practices with higher planned hospitalbirth rates.

In model C more client characteristics and case-specific variables were added. Of these, age, parity, and medical background have a significant effect, further increasing the variance between practices to 0.92. In the next model the structural factors 'degree of urbanisation' and 'distance to the hospital' were added. This reduces the variance among practices to 0.63 . In the last model midwife/practice characteristics were added, reducing the variance between practices to 0.33 . The number of midwives per practice, the attitude to pregnancy and labour management, and the assessment of consultations with obstetricians have no significant influence. Attitude to home-birth and to non- medical reasons for hospital birth are both important factors. The variation in model E is $35.9 \%$ of that in model C $(0.33 / 0.92)$, which means that $64.1 \%$ of the variation between practices is explained.

Because the referral rate to specialist care was such an important factor in the hospital birth rate, and because there was a large variation in referral rates across practices, we repeated the analysis with the combined referral rate, during pregnancy and during labour, as dependent variable (results not shown). We found that four factors significantly contributed to a reduction of the variation in referral rates: a planned hospital birth, a non-optimal medical condition, a more negative attitude of midwives to nonmedical reasons for hospital birth, and a more negative assessment of consultations with specialist obstetricians. Together with other, statistically non- significant factors, this led to a reduction of the variation in referral rates from $25.6 \%$ to $18.4 \%$, which means that $28 \%$ of the variance is explained.

\section{DISCUSSION}

In this study we have analysed the variation in home-birth rates across 42 midwifery practices in one province in the Netherlands. This province is not typical in all its facets for the Netherlands, which means that the implications of our findings are limited. However, they do give an indication of the way home-birth rates were influenced, that will, at least partly, be recognisable in other areas in the Netherlands as well. We found that client characteristics such as age and parity, and case-specific factors such as medical condition and referral to specialist care, were significant factors in explaining the planned and actual hospital-birth rate in a midwifery practice. They cannot, however, explain the difference between practices. It is known from earlier research that nulliparous women and younger women more often than others prefer to give birth in hospital (Kleiverda 1989, SIG 1991). We also 
know that nulliparous women have a higher chance of referral to specialist care and, therefore, a higher chance of actually giving birth in hospital (Eskes 1989, SIG 1991). Although the significance of these factors in explaining the hospital-birth rate is confirmed by our analysis, the use of a multilevel model shows that the difference between practices is primarily related to other factors: structural factors and midwife/practice characteristics.

The distance to hospital and the midwife's attitudes to home-birth and to non-medical reasons for hospital birth were significant factors in explaining the variation across practices in both planned and actual hospital-birth rates. This means that midwives themselves, through their attitudes, have a significant influence on the home- (or hospital-) birth rate in their practice. It shows that in practices, where the midwives have strong preferences for home-birth, and see very few non-medical reasons for hospital birth, the hospital-birth rate is lower and, therefore, the home-birth rate is higher.

The expected relationship between degree of urbanisation and home-birth or hospital-birth rate is not confirmed in our analysis. The reason is that, while the average home-birth rate of cities with more than 100000 inhabitants is $21.3 \%$, one of the three such cities in our study area had a home-birth rate of 54\% (CBS 1995). This is even higher than the average home-birth rate in rural areas.

The finding that obstetric history and medical condition appear to be statistically significant factors in the planned birth place (especially for parous women), and that non-optimal medical condition is a significant factor for referral to specialist care, may indicate the appropriateness of that choice for those women. Is it possible that they anticipated their increased likelihood of referral? Earlier research has already shown that parous women who plan a hospital birth are significantly more often referred during labour than parous women who plan a home-birth (Wiegers et al. 1996). On the other hand, planning a hospital birth is in itself a significant factor for referral to specialist care, indicating that resources are more likely to be used if they are closer at hand. Moreover, the client characteristics and case-specific factors cannot ex- plain the variation in referral rates across practices.

What is significant in explaining that variation is the opinion of the midwives on non-medical reasons for hospital birth and the midwives' assessment of the consultations with obstetricians. The referral rate is higher in practices where midwives consider that there are very few non-medical reasons for hospital birth and in practices where midwives are less positive about their consultations with obstetricians. In our analysis the opinion on advising hospital birth for non-medical reasons is not combined with a strong preference for home-birth. Because it is related to both planned and actual hospital-birth rate, this could be interpreted as reluctance to go to the hospital for non-medical reasons. Combined with the more negative assessment of consultations, this could indicate that the higher referral rates in these practices are related to unsatisfactory working relationships between midwives and hospitals. As is shown in the study by van der Lugt et al. (1991), close co-operation between midwives and obstetricians can reduce the referral rate without jeopardising an adequate level of care for all. The proportions of planned hospital birth and of referral to specialist care are the most important predictors of the actual hospital-birth rate of women receiving midwifery care. As we have shown, both can be influenced by a positive attitude to home-birth, a critical approach to non-medical reasons for hospital birth, and good co-operation between midwives and obstetricians. Our conclusion, therefore, is that midwives themselves can play an important role in maintaining or improving the home-birth rate in their own practice, and thereby in the Netherlands, by being aware of and using the influence of their own attitudes on the choices their clients make about home or hospital birth.

\section{ACKNOWLEDGEMENT}

This study was supported by a grant from `Het Praeventiefonds' (the Prevention fund), nr. 28-1644. 
Wiegers, T.A., Zee, J. van der, Kerssens, J.J., Keirse, M.J.N.C.

Variation in home-birth rates between midwifery practices in the Netherlands.

Midwifery: 16, 2000, nr. 2, p. p. 96-104

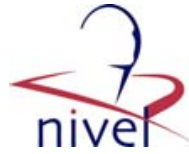

\section{TABLES AND FIGURES}

Table I Independent variables included in the multilevel analysis

\begin{tabular}{ll}
\hline Variable name & Description \\
\hline Client characteristics & \\
age $<25$ & dummy for client's age $<25$ years (reference category $=25-3 \mid$ ) \\
age $>31$ & dummy for client's age $>3$ years (reference category $=25-3 \mid$ ) \\
parity & client's parity $(0=$ nulliparous, I = parous) \\
planned & planned place of birth $(0=$ home, I = hospital)
\end{tabular}

\section{Case-specific factors}

medical

obstetric

medical condition before and during pregnancy $(0=$ optimal, $I=$ not optimal $)$

referral I

obstetric history $(0=$ optimal, $\mathrm{I}=$ not optimal $)$

referral 2

dummy for referral before labour (reference category = no referral)

dummy for referral during labour (reference category $=$ no referral)

\section{Midwife/practice characteristics}

practice

at titude-labour

at titude-home

reason-hospital

assessment

\section{Structural factors}

urban I

urban 2

distance-minutes number of midwives per practice $(\mathrm{I}-4)$

attitude to management of pregnancy and labour ( $I=$ active, $2=$ intermediate, $3=$ expectant $)$ attitude to home-birth (five-point scale: $\mid$ = positive, 5 = negative)

recommend hospital birth for non-medical reasons (five-point scale, I = never, 5 = always) assessment of consultations ( $\mathrm{I}=$ positive, 2 = intermediate, 3 = negative)

dummy for small town (reference category = rural area)

dummy for city (reference category = rural area)

mean distance to hospital in minutes

Table 2 Distribution of independent variables included in the multilevel analysis

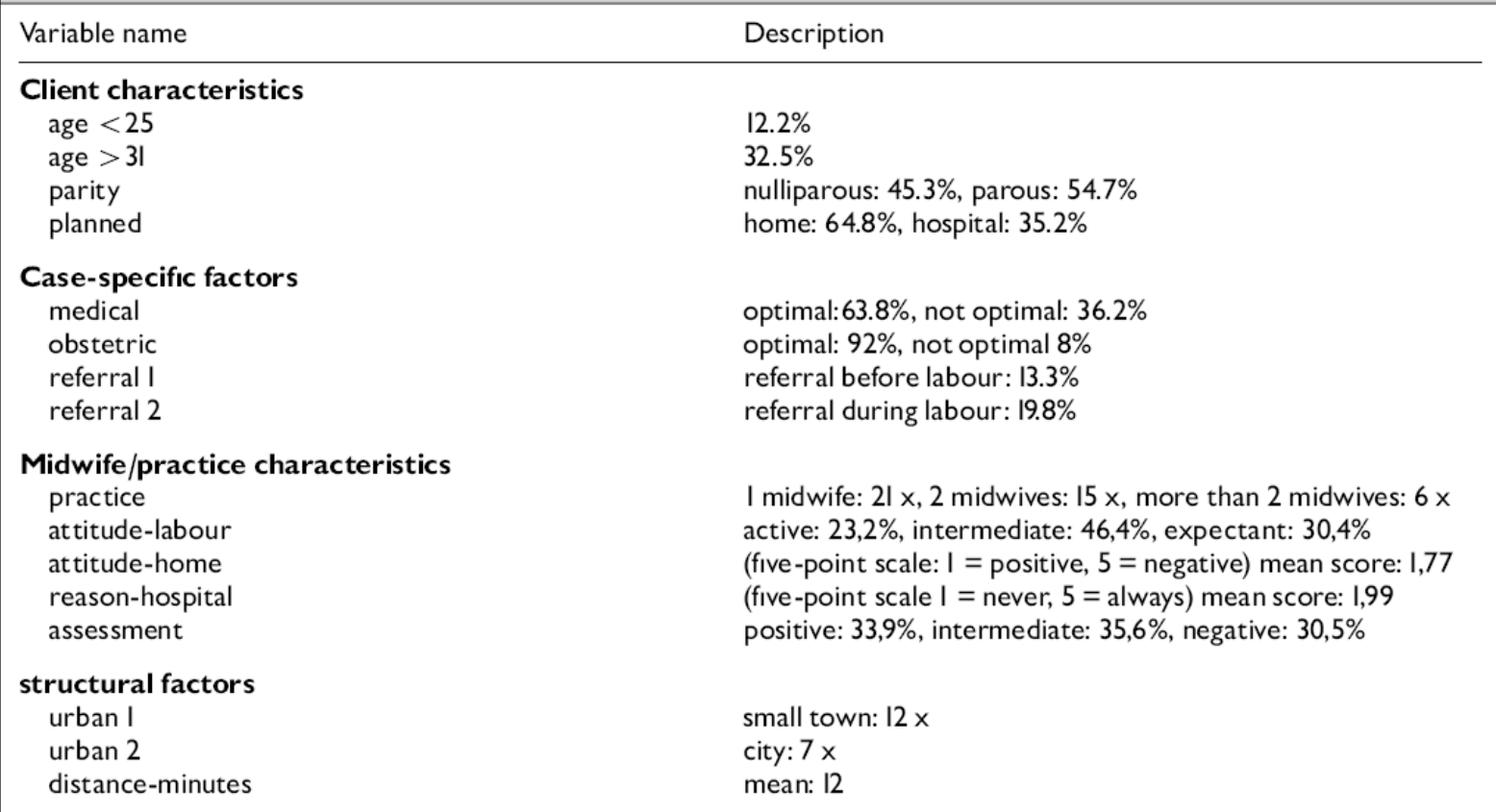


Wiegers, T.A., Zee, J. van der, Kerssens, J.J., Keirse, M.J.N.C.

Variation in home-birth rates between midwifery practices in the Netherlands.

Midwifery: 16, 2000, nr. 2, p. p. 96-104

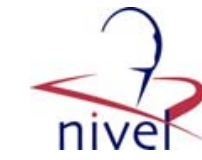

Table 3 Model estimates (and standard error) for the variance in planned bir th place between practices

\begin{tabular}{|c|c|c|c|c|}
\hline \multirow[b]{2}{*}{ Variable* } & \multicolumn{4}{|c|}{ Model } \\
\hline & $A$ & B & C & $\mathrm{D}$ \\
\hline Constant & $-0.58(0.13)$ & $-0.64(0.14)$ & $0.42(0.39) \mathrm{ns}$ & I.I5 (0.92)ns \\
\hline $\begin{array}{l}\text { age }<25 \\
\text { age }>31 \\
\text { parity } \\
\text { obstetric } \\
\text { medical }\end{array}$ & & $\begin{array}{c}0.69(0.10) \\
-0.03(0.07) \mathrm{ns} \\
-0.34(0.07) \\
0.73(0.12) \\
0.26(0.07)\end{array}$ & $\begin{array}{c}0.72(0.10) \\
-0.03(0.08) \mathrm{ns} \\
-0.35(0.07) \\
0.75(0.12) \\
0.26(0.07)\end{array}$ & $\begin{array}{c}0.77(0.11) \\
-0.04(0.08) \mathrm{ns} \\
-0.38(0.07 \\
0.79(0.12) \\
0.27(0.07)\end{array}$ \\
\hline $\begin{array}{l}\text { urbanl } \\
\text { urban2 } \\
\text { distance-minutes }\end{array}$ & & & $\begin{array}{l}-0.12(0.30) \mathrm{ns} \\
-0.58(0.37) \mathrm{ns} \\
-0.08(0.02)\end{array}$ & $\begin{array}{l}0.10(0.24) \mathrm{ns} \\
0.08(0.32) \mathrm{ns} \\
-0.05(0.02)\end{array}$ \\
\hline $\begin{array}{l}\text { practice } \\
\text { attitude-labour } \\
\text { attitude-home } \\
\text { reason-hospital } \\
\text { assessment }\end{array}$ & & & & $\begin{array}{c}0.13(0.12) \mathrm{ns} \\
0.14(0.14) \mathrm{ns} \\
1.03(0.22) \\
0.90(0.21) \\
-0.00(0.13) \mathrm{ns}\end{array}$ \\
\hline $\begin{array}{l}\text { Variation among } \\
\text { practices }\end{array}$ & $0.68(0.16)$ & $0.68(0.16)$ & $0.58(0.14)$ & $0.27(0.07)$ \\
\hline
\end{tabular}

*for fur ther explanation of these variables see Table I

ns $=$ not significant

Table 4 Model estimates (and standard error) for the variance in actual birth place between practices

\begin{tabular}{|c|c|c|c|c|c|}
\hline \multirow[b]{2}{*}{ Variable* } & \multicolumn{5}{|c|}{ Model } \\
\hline & A & B & C & D & $E$ \\
\hline Constant & $0.10(0.12) \mathrm{ns}$ & $-3.24(0.19)$ & $-2.98(0.22)$ & $1.59(0.50)$ & $0.10(1.29) \mathrm{ns}$ \\
\hline Planned & & $4.58(0.15)$ & $4.59(0.16)$ & $4.95(0.17)$ & $5.14(0.18)$ \\
\hline Referral I & & $7.16(0.44)$ & $6.86(0.45)$ & $7.29(0.43)$ & $7.61(0.43)$ \\
\hline Referral 2 & & $9.53(1.04)$ & $9.37(1.04)$ & $9.83(1.02)$ & $10.21(1.00)$ \\
\hline age $<25$ & & & $0.1 \mathrm{l}(0.22) \mathrm{ns}$ & $0.12(0.24) \mathrm{ns}$ & $0.12(0.26) \mathrm{ns}$ \\
\hline age $>31$ & & & $-0.39(0.15)$ & $-0.42(0.16)$ & $-0.44(0.17)$ \\
\hline parity & & & $-0.44(0.15)$ & $-0.45(0.16)$ & $-0.46(0.17)$ \\
\hline obstetric & & & $0.19(0.23) \mathrm{ns}$ & $0.17(0.24) \mathrm{ns}$ & $0.14(0.25) \mathrm{ns}$ \\
\hline medical & & & $0.35(0.16)$ & $0.34(0.17)$ & $0.32(0.18) \mathrm{ns}$ \\
\hline urban I & & & & $0.27(0.37) \mathrm{ns}$ & $0.29(0.35) \mathrm{ns}$ \\
\hline urban 2 & & & & $-0.57(0.43) \mathrm{ns}$ & $0.38(0.43) \mathrm{ns}$ \\
\hline distance-minutes & & & & $-0.13(0.03)$ & $-0.13(0.03)$ \\
\hline practice & & & & & $-0.27(0.17) \mathrm{ns}$ \\
\hline at titude-labour & & & & & $-0.13(0.20) \mathrm{ns}$ \\
\hline at titude-home & & & & & $0.92(0.3 \mathrm{I})$ \\
\hline reason-hospital & & & & & $0.80(0.30)$ \\
\hline assessment & & & & & $0.23(0.18) \mathrm{ns}$ \\
\hline $\begin{array}{l}\text { Variation among } \\
\text { practices }\end{array}$ & $0.56(0.13)$ & $0.87(0.24)$ & $0.92(0.25)$ & $0.63(0.19)$ & $0.33(0.13)$ \\
\hline
\end{tabular}




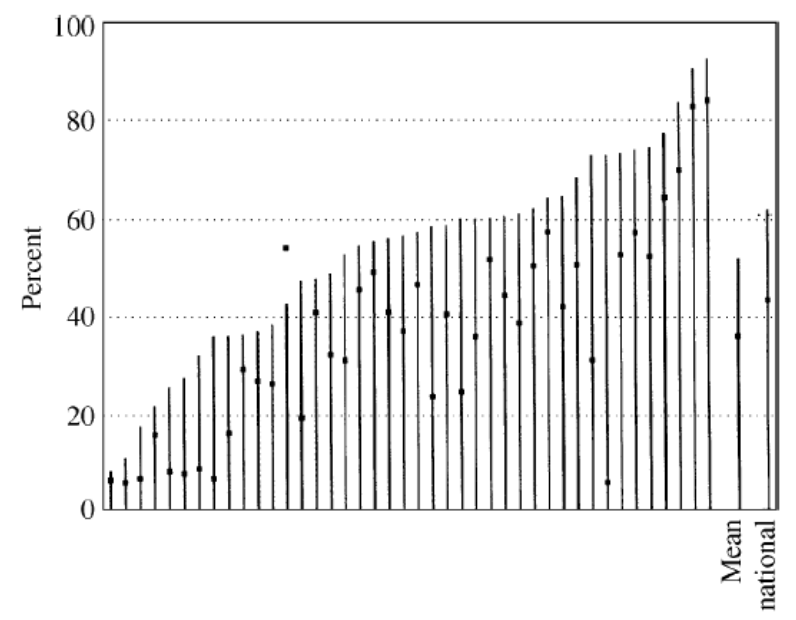

Fig. I Percentage of planned $(=$ dot $)$ and actual $(=$ line $)$ hospital bir ths per practice

\section{REFERENCES}

1. CBS 1995 Births by obstetric assistance and place of delivery, 1992. Maandber Gezondheid (CBS) 14(2): 16

2. Coulter A, Noone A, Goldacre M.1989 General practitioners' referrals to specialist outpatients clinics. British Medical Journal 299: 304

3. Damstra-Wijmenga SMI 1984 Home confinement: the positive results in Holland. Journal of the Royal College of General Practitioners 256: 425

4. Eskes M 1989 Het Wormerveer onderzoek: meerjarenonderzoek naar de kwaliteit van de verloskundige zorg rond een vroedvrouwenpraktijk. Zaandijk: Heynis \& Schipper, Thesis

5. Hingstman L, Boon H 1988 Obstetric care in the Netherlands: regional differentiation in home delivery. Social Science and Medicine 26: 71

6. Jabaaij L, Meijer W 1996 Home-birth in the Netherlands: midwifery-related factors of influence. Midwifery 12: 129-135

7. Kleiverda G 1989 Transition to parenthood and home or hospital confinement: a prospective study in nulliparous women in the Netherlands. In: van Hall EV, Everaerd W (eds) The free woman, women's health in the 1990s. The Parthenon Publishing Group, New Jersey

8. Kleiverda G, Steen AM, Andersen I et al. 1990 Place of delivery in the Netherlands: maternal motives and background variables related to preferences for home or hospital confinement. European Journal of Obstetric, Gynaecological and Reproductive Biology 36: 1

9. Newton J, Hayes V, Hutchinson A 1991 Factors influencing general practitioners' referral decisions. Family Practice 8: 308

10. Rice N, Leyland A 1996 Multilevel models: applications to health data. Journal of Health Services Research Policy 1: 154

11. SIG Zorginformatie 1992 Jaarboek Verloskunde 1991 SIG, Utrecht.

12. Vallgårda S 1996 Hospitalization of deliveries: the change of place of birth in Denmark and Sweden from the late nineteenth century to 1970. Medical History 40: 173

13. van der Lugt BJAM, Remmink AJ, Canten J et al. 1991 Enkele verloskundige resultaten bij selectie volgens de nieuwe medische indicatielijst. Ned Tijdschr Obstet Gynaecol 104: 54

14. Wiegers TA, Keirse MJNC, van der Zee J et al. 1996 Outcome of planned home and planned hospital births in low risk pregnancies: prospective study in midwifery practices in the Netherlands. British Medical Journal 313: 1309

15. Wiegers TA 1997 Home or hospital birth. A prospective study of midwifery care in the Netherlands. Unpublished thesis, University of Leiden, Leiden

16. Woodhouse G, Rasbash J, Goldstein H et al. 1995 A guide to MLN for new users. Multi level models project, Institute of education, University of London 